\title{
Combustion and Flame
}

\section{Application of machine learning for filtered density function closure in MILD combustion --Manuscript Draft--}

\begin{tabular}{|c|c|}
\hline Manuscript Number: & CNF-D-20-00762R1 \\
\hline Article Type: & Full Length Article \\
\hline Keywords: & $\begin{array}{l}\text { Machine learning; Deep neural networks; Filtered density function; MILD combustion; } \\
\text { Subgrid scale modelling }\end{array}$ \\
\hline Corresponding Author: & $\begin{array}{l}\text { Zhi X. Chen, Ph.D. } \\
\text { University of Cambridge } \\
\text { Cambridge, UNITED KINGDOM }\end{array}$ \\
\hline First Author: & Zhi X. Chen \\
\hline \multirow[t]{7}{*}{ Order of Authors: } & Zhi X. Chen \\
\hline & Salvatore lavarone \\
\hline & Golnoush Ghiasi \\
\hline & Veeraraghavan Kannan \\
\hline & Giuseppe D'Alessio \\
\hline & Alessandro Parente \\
\hline & Nedunchezhian Swaminathan \\
\hline Abstract: & $\begin{array}{l}\text { A machine learning algorithm, the deep neural network ( DNN ) Ifootnote \{The DNN } \\
\text { code and a sample training dataset are available for public access at lurl \{ https :/l } \\
\text { github . com / cz5224043 /ml-mild-combustion\}.\}, is trained using a comprehensive } \\
\text { direct numerical simulation ( DNS ) dataset to predict joint filtered density functions ( } \\
\text { FDFs ) of mixture fraction and reaction progress variable in Moderate or Intense Low- } \\
\text { oxygen Dilution (MILD) combustion. The important features of the DNS cases include } \\
\text { mixture fraction variations, turbulent mixing lengths, exhaust gas recirculation ( EGR ) } \\
\text { dilution levels, etc., posing a great challenge for data-driven modelling. The DNN } \\
\text { architecture is built and optimised with extreme care to achieve high robustness and } \\
\text { accuracy, resorting to dimensionality reduction techniques such as principal } \\
\text { component analysis ( PCA ) to identify and remove the outliers in the training data. To } \\
\text { better interpret the predictive ability of the DNN, two analytical joint FDF models } \\
\text { respectively using two independent } \$ \text { lbeta } \$ \text { and Itextit \{copula\} distributions, are also } \\
\text { employed for a detailed comparison with the DNS data. } \\
\text { The FDFs in MILD combustion behave differently compared to those in conventional } \\
\text { flames because the reaction zones are more distributed. They generally exhibit non- } \\
\text { regular (neither Gaussian nor bi-modal) distributions and strong cross correlations, } \\
\text { which cannot be captured adequately by the analytical models. However, the DNN is } \\
\text { well suited for this physico -chemically complex problem and its predictions are in } \\
\text { excellent agreement with the DNS data for a broad range of mixture conditions and } \\
\text { filter sizes. Furthermore, Itextit \{a priori\} assessment is conducted for filtered reaction } \\
\text { rate closure. It is found that the DNN model significantly outperforms the analytical } \\
\text { models for all cases showing very good predictions for the filtered reaction rate for a } \\
\text { range of filter sizes. The DNN prediction improves as the filter size becomes larger } \\
\text { than the characteristic reaction zone thickness while the analytical models works } \\
\text { relatively better for smaller filter sizes. This is a clear advantage for the DNN to be } \\
\text { used in practical LES applications. }\end{array}$ \\
\hline
\end{tabular}

